University of Nebraska - Lincoln DigitalCommons@University of Nebraska - Lincoln

2004

\title{
Smart Materials, Precision Sensors/Actuators, Smart Structures, and Structronic Systems
}

\author{
H. S. Tzou \\ University of Kentucky \\ H.-J. Lee \\ Structural Mechanics and Dynamics Branch, NASA Glenn Research Center, Cleveland, Ohio \\ S. M. Arnold \\ Life Prediction Branch, NASA Glenn Research Center, Cleveland, Ohio
}

Follow this and additional works at: http://digitalcommons.unl.edu/nasapub

Tzou, H. S.; Lee, H.-J.; and Arnold, S. M., "Smart Materials, Precision Sensors/Actuators, Smart Structures, and Structronic Systems" (2004). NASA Publications. 200.

http://digitalcommons.unl.edu/nasapub/200

This Article is brought to you for free and open access by the National Aeronautics and Space Administration at DigitalCommons@University of Nebraska - Lincoln. It has been accepted for inclusion in NASA Publications by an authorized administrator of DigitalCommons@University of Nebraska - Lincoln. 


\title{
Smart Materials, Precision Sensors/Actuators, Smart Structures, and Structronic Systems
}

\author{
H. S. TZOU \\ Department of Mechanical Engineering, University of Kentucky, \\ Lexington, Kentucky, USA \\ H.-J. LEE \\ Structural Mechanics and Dynamics Branch, NASA Glenn Research Center, \\ Cleveland, Ohio, USA \\ S. M. ARNOLD \\ Life Prediction Branch, NASA Glenn Research Center, Cleveland, Ohio, USA

\begin{abstract}
Many electroactive functional materials have been used in small- and microscale transducers and precision mechatronic control systems for years. It was not until the mid-1980s that scientists started integrating electroactive materials with large-scale structures as in situ sensors and/or actuators, thus introducing the concept of smart materials, smart structures, and structronic systems. This paper provides an overview of present smart materials and their sensor/actuator/structure applications. Fundamental multifield optomagnetopiezoelectric-thermoelastic behaviors and novel transducer technologies applied to complex multifield problems involving elastic, electric, temperature, magnetic, light, and other interactions are emphasized. Material histories, characteristics, material varieties, limitations, sensor/actuator/structure applications, and so forth of piezoelectrics, shape-memory materials, electro- and magnetostrictive materials, electro- and magnetorheological fluids, polyelectrolyte gels, superconductors, pyroelectrics, photostrictive materials, photoferroelectrics, magneto-optical materials, and so forth are thoroughly reviewed.
\end{abstract}

\section{INTRODUCTION}

The concepts of smart, intelligent, and adaptive materials and structures originated in the mid-1980s in an attempt to describe the newly emerging research area of integrating electroactive functional materials into large-scale structures as in situ sensors and actuators. Previously, electroactive materials had only been used in small- and microscale transducers and precision mechatronic (mechanical + electronic) control systems. The general perception of smart, intelligent, and adaptive materials or structures implies an ability to be clever, sharp, active, fashionable, and sophisticated. However, in reality, materials or structures can never achieve true intelligence or reasoning without the addition of artificial intelligence

Received 22 July 2003; accepted 22 July 2003.

Address correspondence to H. S. Tzou, Department of Mechanical Engineering, University of Kentucky, Lexington, Kentucky 40506-0503, USA. E-mail: hstzou@engr.uky.edu 
Table 1

Common smart materials and their milestone years

\begin{tabular}{|c|c|c|c|}
\hline $\begin{array}{l}\text { Piezoelectrics } \\
\text { (1880) } \\
\text { pyroelectrics } \\
\text { (315 B.C.) }\end{array}$ & $\begin{array}{l}\text { Shape-memory } \\
\text { materials (1932) }\end{array}$ & $\begin{array}{l}\text { Electro- and } \\
\text { magnetostrictive } \\
\text { materials (1954/1840) }\end{array}$ & $\begin{array}{l}\text { Electro- and } \\
\text { magnetorheological } \\
\text { fluids }(1784 / 1947)\end{array}$ \\
\hline $\begin{array}{l}\text { Polyelectrolyte } \\
\text { gels (pH } \\
\text { muscles) } \\
\text { (1949) }\end{array}$ & $\begin{array}{l}\text { Photostrictive } \\
\text { materials (1974); } \\
\text { photovoltaic } \\
\text { materials }\end{array}$ & Superconductors (1911) & Liquid crystals \\
\hline Optical fibers & $\begin{array}{l}\text { Electro- } \\
\quad \text { luminescence } \\
\text { particles }\end{array}$ & $\begin{array}{l}\text { Magneto-optical, } \\
\text { electromagnets, } \\
\text { magnetoelastic materials }\end{array}$ & Electrostatic materials \\
\hline
\end{tabular}

through computers, microprocessors, control logic, and control algorithms. Accordingly, the materials can only be active and the structures could ultimately be intelligent. Furthermore, the synergistic integration of smart materials, structures, sensors, actuators, and control electronics has redefined the concept of structures from a conventional passive elastic system to an active or adaptive (lifelike) multifunctional structronic (structure + electronic) system with inherent capabilities for self-sensing, diagnosis, and control capabilities [1-4]. Thus, the goal of this paper is to review the fundamental characteristics, design principles, and practical applications of key smart materials as outlined in Table 1. The smart materials examined include piezoelectrics, shape-memory alloys, electrostrictive materials, magnetostrictive materials, electrorheological fluids, magnetorheological fluids, polyelectrolyte gels, pyroelectrics, photostrictive materials, photoferroelectric materials, magneto-optical materials, and superconducting materials. The requirements for multifield optothermoelectromagnetomechanical systems applied to complicated multifield control problems coupling elastic, thermal, electric, magnetic, and light interactions are also discussed.

\section{PIEZOELECTRIC MATERIALS}

The Curie brothers (Jacques and Pierre) observed electric field generations on quartz crystals when subjected to mechanical forces in 1880. (Piezo means "press" in Greek.) They consequently also observed strain generations when the crystal was subjected to electric fields. Piezoelectricity is, in general, an electromechanical phenomenon coupling the elastic (dynamic coupling) field and the electric (static coupling) field. A piezoelectric material responds to mechanical forces/pressures and generates electric charges/voltages, which is referred to as the direct piezoelectric effect. Conversely, electric charges/fields applied to the material can induce mechanical stresses or strains, and this is called the converse piezoelectric effect [5] (see Figure 1). Usually, the direct effect is the basis for sensor applications and the converse effect is for precision actuation and manipulation in control applications. The actuation stroke ranges from nano-, to micro-, to millimeter scales, depending on configurations and designs or with/without mechanical amplifications or deductions via lever systems. Note that, at low electric field, piezoelectricity is a first-order effect that produces a strain proportional to the electric field and the direction of the displacement dependent on the sign of the electric field [6]. However, as the electric field increases, electromechanical hysteresis 


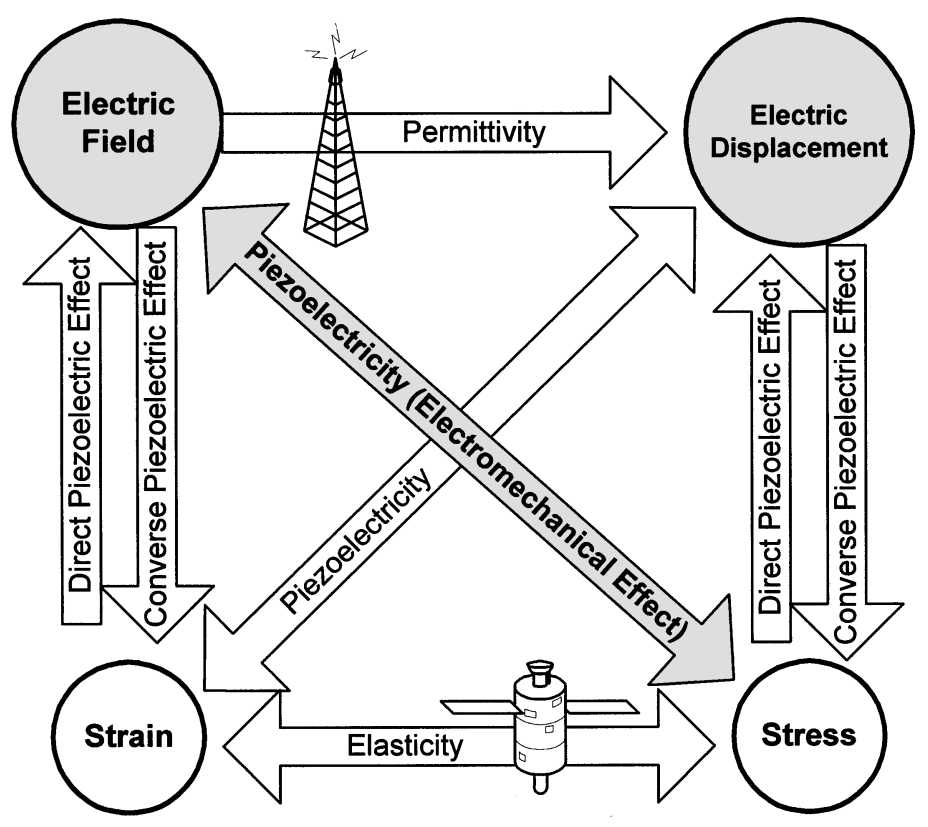

Figure 1. Piezoelectricity—an electromechanical coupling.

appears and its domain grows at strong electric fields, which can cause servodisplacement control problems in large-stroke precision actuation of piezoelectric actuators.

Many natural and synthetic materials exhibit piezoelectric properties [7], which can be classified into (1) natural crystals, (2) liquid crystals, (3) noncrystalline materials (4) textures, and (5) synthetic piezoelectric materials, (see Table 2). Note that raw synthetic materials are usually isotropic and nonpiezoelectric. They become anisotropic and piezoelectric only after the poling process that involves applying a high electric field at an elevated temperature. The field aligns the molecular dipoles in the material and the dipoles are then fixed into the aligned orientation in the structure when the material is cooled while maintaining the strong field. The poled piezoelectric will deform in the presence of an electric field and polarize when subject to mechanical stress. Because synthetic materials (e.g.,

Table 2

Common piezoelectric materials

Natural crystals

Liquid crystals

Noncrystalline materials

Textures

Synthetic piezoelectric materials
Quartz, Rochelle salt, ammonium phosphate, etc.

Glass rubber, paraffin, etc.

Bone, wood, etc.

(a) Piezoceramics: lead zirconate titanate (PZT), barium titanate, lead niobrate, lead lanthinum zirconate titanate (PLZT), etc.

(b) Crystallines: ammonium dihydrogen phosphate, lithium sulfate, etc.

(c) Piezoelectric polymer: polyvinylidene fluoride $\left(\mathrm{PVDF}\right.$ or $\left.\mathrm{PVF}_{2}\right)$, etc. 
PZT and PLZT) and polymers (e.g., PVDF) can be fabricated into arbitrary geometries and shapes, they are very popular in many sensor and actuator applications.

Fundamental theories on piezoelectricity, piezothermoelasticity, and optopiezothermoelasticity have been proposed and refined over the years [6, 8-22]. Engineering application of piezoelectric materials started with a depth-sounding device, based on Rochelle salt, invented by Langevin in 1917. Novel piezoelectric devices were invented and applied to a variety of engineering applications [2-4, 23-26]. Many other sensors (e.g., accelerometers, pressure transducers, force transducers, microphones, etc.), actuators (precision manipulators, robot manipulators, ultrasonic motors, driving mechanism for scanning tunneling microscopes, etc.), smart structures, and structronic systems (e.g., helicopter rotor blades, airplane wings, space structures, precision trusses, etc.) have been documented. (In fact, the area of smart structures and structronics started with the distributed piezoelectric sensing and control research in the early 1980s.) New devices are being invented and patented every year. Table 3 gives a list of sample applications.

Recent development of adaptive (or smart) structures and microelectromechanical systems (MENS) further integrate piezoelectrics with structures and control electronics, in both static and dynamic applications. Examples include aerospace/aircraft structures [27, 28], robot manipulators [29], vibration controls and isolations, high-precision devices, microsensors/actuators, thin-film MEMS [30], health monitoring [31], microdisplacement actuation and control [25], and so on. Additional applications in smart structures and structronic systems encompass distributed structural control [16, 32-36], rotor dynamics control [37], self-sensing actuators [38-40], orthogonal modal sensors/actuators [41-43], space truss members [44], noise control [45], vibration isolators [46], active constrained damping [47], morphing of wings and blades [48], microscopic neural-sensing and actuation characteristics of conical, paraboloidal, toroidal and spherical structronic shells [49-55], and so on. Other recent practical applications include piezoelectrically damped skis, control of aeroelastic wing flutter, optical metering truss control, helicopter blade control, noise reduction, biomedical applications, and ultrasonic motors [56-61]. Note that although Table 3 summarizes sample applications of piezoelectrics, most of these applications can also be achieved by many other smart materials, for example electro- and magnetostrictive materials, shape-memory materials, and so forth with different design principles due to their individual material characteristics.

\section{SHAPE MEMORY MATERIALS}

Shape-memory-like behavior was first observed in a sample of gold cadmium (AuCd) by Chang and Read in 1932. This shape transformation was later observed in brass in 1938, and also in an AuCd bend bar in 1951. It was not until 1962 that a full shape-memory effect was observed in a series of nickel-titanium alloys by Buehler, Gilfrich and Wiley. This shape-memory alloy (SMA) is now called Nitinol (NiTi) and is the most commercially known SMA [62]. Not only does this alloy exhibit excellent shape-memory characteristics but it can also have variable transformation temperatures by changing its chemistry or composition. Other alloys have also been tested for the effect; however, Nitinol proves to be the most commercially attractive SMA material. Note that although the shape-memory effect is predominately found in metal alloys, certain ceramics and polymers also exhibit the shape-memory effect.

Mechanically deformed SMA, by raising its temperature, can be made to return to its original shape, which is known as the shape-memory effect. At low temperature, the SMA crystalline structure exhibits a needle-like structure called martensite, and it exhibits 
Table 3

Sample applications

Sensors

Actuators

Structures

Machines and mechanical systems

Medical and biomedical applications

Robotics and mechatronic systems

Smart structures and structronic systems
Accelerometer, pressure transducer, force transducer, noise/acoustic sensor, microphone, impact transducer, distributed sensor, orthogonal (modal) sensor, health monitoring, etc.

Precision manipulator, pressure generator, ink/fuel injection, displacement actuator, vibration isolation, vibration and noise control, ultrasonic motors, distributed control, constrained layer damping, passive shunt damping, orthogonal (modal) actuator, self-sensing actuator, active structures, smart composites, etc.

Vibration, noise, stress, strain, health monitoring, measurements (e.g., flow, pressure, force, impact), morphing, etc.

Vibration and noise (monitoring and control), strength, stress, strain, health monitoring and diagnosis, optical systems, measurements (e.g., force, acceleration, pressure, impact, noise), rotor control, etc.

Disposable sensors, ultrasonic devices, precision drives and control (e.g., scanning tunneling microscopes, manipulators, etc.)

Precision actuation, manipulation, control, precision/micro robots, robot grippers, flexible robot control, microelectromechanical systems (MEMS), micro sensor/actuator, etc.

Adaptive structures and composites, structural control, adaptive geometry and shape control, adaptive aircraft wings or helicopter blades (morphing), noise and vibration control, damage detection, health monitoring, self-sensing actuators, damage repairs, precision truss structures, positioning, aerospace structures and satellites, etc.

a strong cubic structure called austenite when heated. The different physical properties at the martensitic and the austenitic crystal structures produce the shape-memory effect. While in the martensitic crystal structure, the material is more compliant (lower Young's modulus) than when in the austenitic crystal structure. The austenitic crystal structure is considerably more rigid (higher Young's modulus). The temperature range at which SMAs undergo martensitic transformation depends on several factors, some of which can be altered to fit specific needs. The temperature at which the martensite starts to form varies for different materials and different ratios of metal in shape-memory alloys. In Ni-Ti alloys, the temperature at which the martensite forms can vary from $-200^{\circ} \mathrm{C}$ to $+100^{\circ} \mathrm{C}$ depending on the nickel-to-titanium ratio. $\mathrm{Cu}-\mathrm{Ni}-\mathrm{Al}$ alloys can produce martensitic transformations as high as $200^{\circ} \mathrm{C}$ [63]. The temperature range between the martensitic and austenitic states is also an important factor for SMA applications. The typical range is about 5 to $10^{\circ} \mathrm{C}$ [64]. The other important property of this crystalline transformation is the existence of temperature 

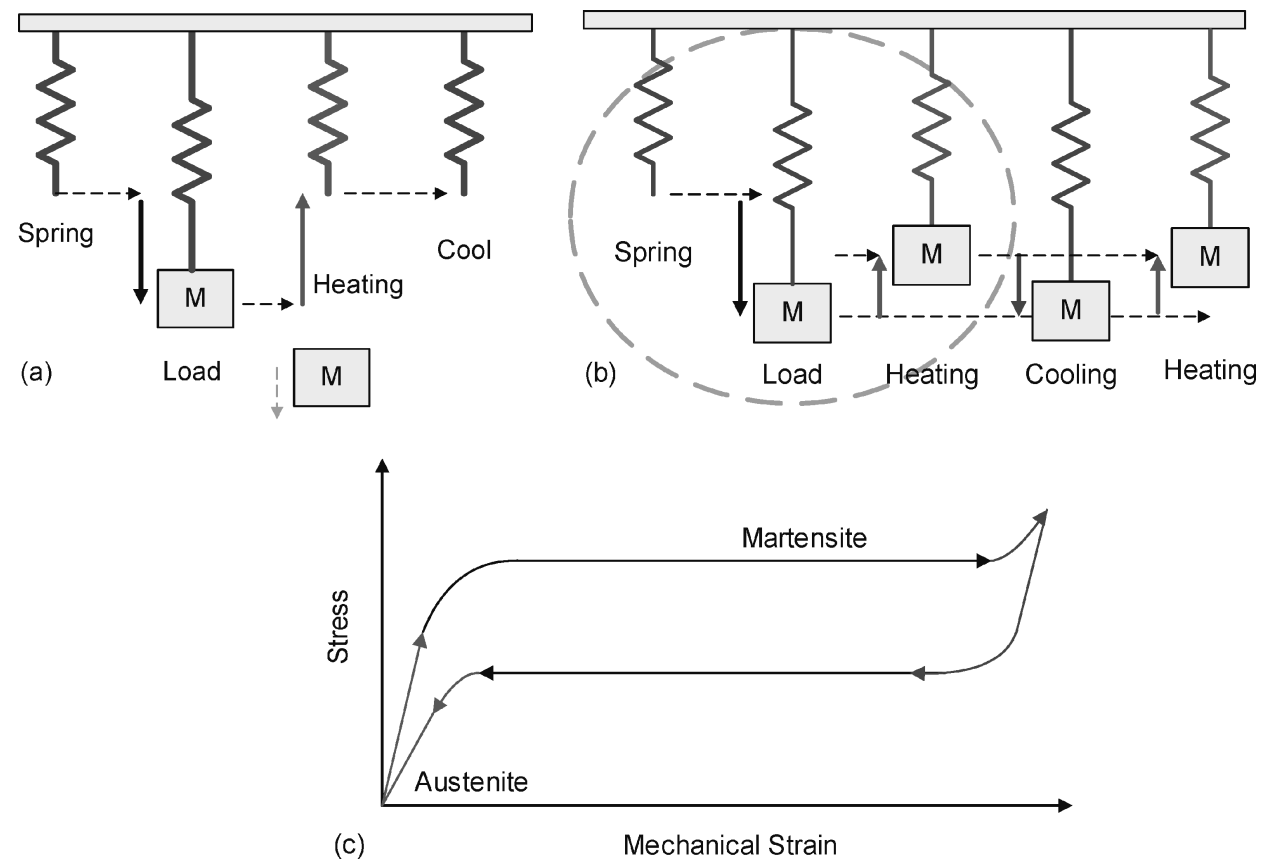

Figure 2. (a) SMA one-way effect, (b) two-way effect, and (c) pseudoelasticity.

hysteresis. This means that the transformation from martensite to austenite occurs at higher temperature while heating, and the transformation from austenite to martensite occurs at a lower temperature upon cooling. The extent of this hysteresis can be quite significant-30 to $50^{\circ} \mathrm{C}$ for common $\mathrm{Ni}-\mathrm{Ti}$ SMAs. Material modifications can either decrease the hysteresis to as low as $15^{\circ} \mathrm{C}$ or as high as $100^{\circ} \mathrm{C}[65]$.

There are three fundamental shape-memory effects: (1) the one-way effect, (2) the two-way effect, and (3) the pseudoelasticity (or superelasticity). Figure 2 illustrates the characteristics of the one-way effect, the two-way effect, and the pseudoelasticity. Plastically deforming an SMA in the martensitic form and recovering its original shape at a higher temperature is known as the one-way effect. This effect is particularly useful in Ni-Ti alloys due to the existence of two yield points. This alloy exhibits a low yield point and a significantly high yield point [65]. Deformations above the first yield point are easily recoverable by heating, but deformations above the second yield point are not recoverable by heating. The typical amount of recoverable deformations is as high as $3-4 \%$ for copper-based alloys and 6-8\% for Ni-Ti alloys [63]. The second effect of SMAs is the two-way effect. This is probably the most widely used and beneficial effect of SMAs. Thermal energy can be efficiently translated into mechanical energy using the two-way effect. If a force is applied to an SMA in the martensitic state, heating above the martensitic transformation temperature while applying the same force will cause the strain in the alloy to be reduced. (That is the same stress that will cause less strain in the austenitic state than in the martensitic state.) This is due to the decreased elasticity of the austenitic state. The force generated during the transformation between the two states is quite significant, and it makes SMAs useful for a number of applications. The third effect exhibited by SMAs is the pseudoelasticity (or superelasticity) that only occurs when the SMA is slightly above its transition temperature. When an alloy is in the austenitic state, a stress-induced martensitic transformation can 
occur. However, because the material is above its transition temperature, ambient thermal energy converts the martensite back to the austenite after the stress is relieved. The material is forcefully transformed back to its previous austenite shape providing a very springy or rubberlike elasticity in the alloy. This effect allows the SMA to have recoverable strain beyond that of most materials. Strain as high as $5 \%$ can be repetitively recovered using $\mathrm{Ni}-$ Ti wires; however, fatigue is a problem [66]. There has been continual research devoted to finding new alloys exhibiting the shape-memory effect. Patents in recent years have shown such alloys as copper, zinc, and aluminum combined with lesser amounts of nickel and titanium.

In 1969, Raychem successfully produced a NiTi hydraulic pipe coupling called Cryofit and it was used in military high-performance hydraulic systems. Interest in SMA products increased greatly in Japan in the 1970s. Recall that the two-way effect can be utilized in a number of different actuators both thermal and electrical. Because the two-way effect works with both normal and shear stresses, a wide range of geometrical configurations can be used as actuators. SMAs can be made into straight wires, helical springs, cantilever springs, wave-washer springs, torsion wires/rods, torsion tubes, and so on. Straight wires and wave-washer springs tend to produce a higher force and a smaller motion than helical springs. The two-way effect can also be achieved without the application of an external force. This requires a special heat-treating process involving prestressing the material at different temperatures. The true two-way effect produces less motion and force and is less well understood than the two-way effect involving an external force. The heat-treatment procedure is also more expensive, making this type of two-way effect less desirable than the external force method [65]. Many SMA applications include SMA prosthetic arms [67], coffee makers, seals and fasteners, blood clot filters, deep fryers, expresso machines, and so on. [64]. Proposals for new applications include wing morphing, circuit breakers, fire dampers, autovent systems, door panel controls, and so forth.

\section{ELECTROSTRICTIVE MATERIALS}

Both electrostrictors and piezoelectrics belong to the ferroelectric family. Piezoelectricity is a first-order effect; however, electrostriction is a second-order (quadratic) effect, that is, the induced strain is proportional to the square of the applied electric field. Thus, the induced strain is independent of the direction of the applied field and the same deformation (direction and magnitude) occurs when the field is reversed (Figure 3).

Electrostriction is usually present in all dielectric materials but is very weak due to the dominating stronger first-order piezoelectric effect. Thus, during the development of piezoelectric applications, the smaller, second-order electrostrictive effect is ignored for most practical purposes. However, materials that have high dielectric constants (high polarizations), such as relaxor ferroelectrics, can exhibit very large electrostrictive strains. Unlike piezoelectrics, the spontaneous polarization in a relaxor ferroelectric does not disappear at a certain Curie temperature, but slowly decays with increasing temperature. This phenomenon might be caused by the diffuse nature of the transition related to a partially disordered distribution of cations in a relaxor ferroelectric, permitting a mixture of pyroelectric and paraelectric phases existing over a wide temperature range. Hence, the dielectric hysteresis in the transition region disappears before the spontaneous polarization, allowing significant electrostriction with minimal hysteresis above and below the nominal transition temperature. Also, strains on the order of $0.1 \%$ are typical for electrostrictors and the material is stable in nature because no electric manipulation of the domains is required to orient dipoles [68]. 


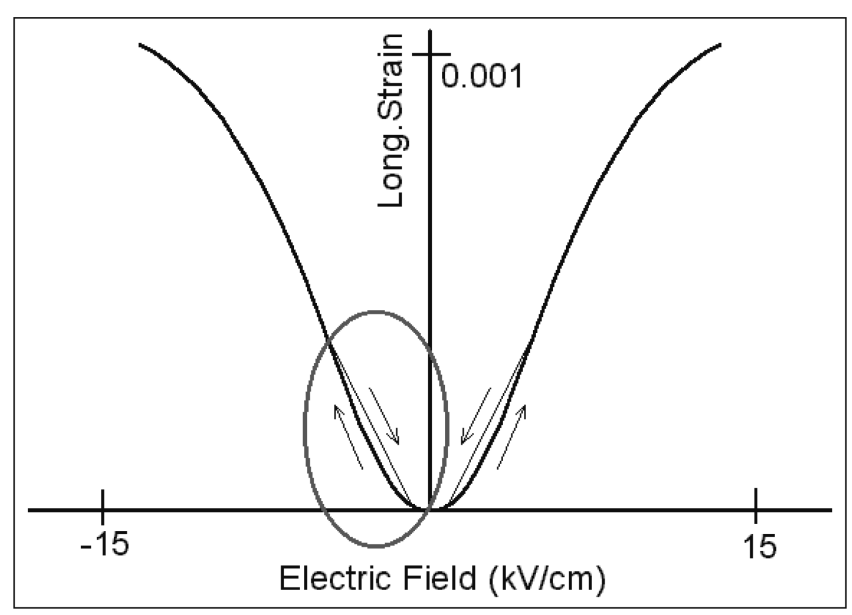

Figure 3. Electrostrictive response.

Lead magnesium niobate, $\mathrm{Pb}\left(\mathrm{Mg}_{1 / 3} \mathrm{Nb}_{2 / 3}\right) \mathrm{O}_{3}(\mathrm{PMN})$, or its solid solutions with lead titanate, $\mathrm{Pb}\left(\mathrm{Mg}_{1 / 3} \mathrm{Nb}_{2 / 3}\right) \mathrm{O}_{3}-\mathrm{PbTiO}_{3}$ (PMN-PT), are the most significant relaxor ferroelectrics commonly used in actuator applications. In 1958, Smolenski and Agranovskaya first discovered PMN, which is described as a relaxor ferroelectric perovskite with an average Curie temperature of about $0^{\circ} \mathrm{C}$. It has a high dielectric constant with a wide temperature range. Materials with a PMN base and operating above the nominal transition temperature will typically have high induced strains $(>0.1 \%)$ and low hysteresis $(<5 \%)$ in fields of moderate intensity $(\sim 1 \mathrm{MV} / \mathrm{m})$ [69]. Electrostrictive PMN is a purely nonpiezoelectric material in which the electrostrictive effect can be strongly distinguished. Note that polymeric electrostrictive materials were also reported in recent years.

However, electrostrictive materials might be more reliable than piezoelectric materials based on certain physical properties such as hysteresis, poling, modulus, temperature effect, external interference, and so on, discussed as follows:

1. Electrostrictive PMN exhibits a negligible hysteresis $(<1 \%)$, which is essential in repeatedly locating and maintaining a setpoint accuracy and open-loop controlled responses.

2. PMN requires no poling, which means it remains stable with no aging or creep commonly found in piezoelectric devices.

3. PMN has a very high elastic modulus $\left(17 \times 10^{6} \mathrm{psi}\right)$ which produces relatively high stiffness, enhancing the force/deflection capability.

4. PMN actuators have negligible thermal growth because the thermal expansion coefficient dissipates very little power. Its high maximum service temperature further allows PMN devices to operate in very harsh environments.

5. PMN also has improved strain sensitivity that reduces the operating voltage below $150 \mathrm{~V}$.

6. PMN produces little or no electrical or magnetic interference with other components. Accordingly, PMN components have replaced many piezoelectric actuators used in precision apparatus because the PMN drift is less than $3 \%$ over two days compared with $10-15 \%$ of a comparable piezoelectric device under loading $[68,70]$.

Precision actuators and displacement transducers are ideal applications of PMN-based materials. Note that both electrostrictive and piezoelectric materials provide accurate 
displacements with a rapid response time in actuator applications. Comparing with electromagnetic actuators, electrostrictive or piezoelectric systems are more compact, consume less power, and have fewer overheating problems. Thus, these materials are open to a wide variety of commercial applications. Practical PMN applications include displacement actuators [71, 72], motors [73], pumps [74, 75], optical scanning systems [76], vibration isolators, tool bits, and so on. One application in optical devices is in the positioning of deformable mirrors, such as those in Hubble Space Telescope. PMN is arranged in an array on the back of the mirror surface, which can control the surface of the mirror reflection. This is especially useful in the precision control of a high-power laser light. Similar technology applies to the optical fiber polarization controlled by the actuator compression of single fibers. The other major application is the development of linear and rotational motors with typical range of motion of several micrometers for each centimeter of electrostrictor. Again, with lever systems, one can either extend or reduce its operation range. Recent development focuses on electrostrictive polymers and multifield coupling theories [77, 78].

\section{MAGNETOSTRICTIVE MATERIALS}

Magnetostriction is also a second-order (quadratic) effect; that is, the induced strain is proportional to the square of the applied magnetic field, which is similar to electrostriction (Figure 3). Thus, its induced strain is independent of the direction of the applied magnetic field and the same deformation (direction and magnitude) occurs when the field is reversed.

Nickel was the first known magnetostrictive material that exhibited strains of approximately 50 parts per million (ppm) or a strain of $50 \mu \mathrm{m}$ in a $1-\mathrm{m}$ rod, commonly called micro strain. In 1963, Alstad and Rhyne discovered that the rare earth element terbium combined with iron produced much larger strains (greater than $1000 \mathrm{ppm}$ ). This giant strain, however, was only achieved at cryogenic temperatures and in the presence of a large magnetic field. In 1972, Clark and Savage finally produced an alloy of terbium, dysprosium, and iron that generated giant strains at room temperature and without the need for large magnetic fields. This new alloy was named Terfenol-D or giant magnetostrictive material. The new material can also produce great forces, fast, high-precision motion, high efficiencies, and high power levels. The material possesses another valuable characteristic: it can efficiently convert energy from an electrical form to a mechanical form and vice versa. This implies that the materials can be applied to both sensor and actuator applications. However, characteristic drawbacks of Terfenol-D include high flammability and brittleness. Note that there has been magnetostrictive polymer development in Japan recently.

A magnetic field causes the Terfenol-D material to increase in length when the magnetizing field is applied parallel to the drive axis. This linear displacement is maximized when the Terfenol-D material is mechanically prestressed and the difference in strain can be as much as $1500-1700 \mathrm{ppm}$. Prestressing the material also tends to increase its linear response at low fields, and varying the prestress actually allows for limited variation in response. As discussed previously, Terfenol-D can provide only positive displacement in the presence of an AC field. To obtain both positive and negative strains, magnetic biasing is required. This biasing effect may be provided by permanent magnets or other external DC supply sources. (Note that piezoelectric PZT actuators are also often biased with a DC voltage.) Device applications can be mainly divided into two categories, (1) sensors and, (2) actuators, in addition to mechatronic and structronic systems. Precision actuator applications include magnetostrictive clamps [79], direct-drive motors [80], self-biased modular drivers [81], self-sensing struts [82], magnetostrictive shakers [83], and so on. Sensor applications are omnidirectional loudspeakers [84], low-frequency sound transducers [85], helical line hydrophones [86], and so forth. 


\section{ELECTRO- AND MAGNETORHEOLOGICAL FLUIDS}

Usually, temperature and pressure influence kinematic viscosity of most fluids. However, the viscosity of electro- and magnetorheological fluids is controlled by their molecular structure and activated by external electric or magnetic fields. Thus, the viscosity of an electro- and magnetorheological fluid can be altered without changing the temperature or pressure of the fluid. Active rheological fluids can be grouped into (1) electrorheological (ER) fluids, (2) magnetorheological (MR) fluids, and (3) ferrofluids. These fluids change their physical properties when an electrical or magnetic field is applied. Usually, ER and MR fluids contain micron-sized particles dispersed in a carrier liquid (usually oil) and they develop a yield stress in response to an electric or magnetic field. However, ferrofluid contains nanometer-sized particles dispersed in an oil. The particles attract with a magnetic field applied; however, there is no yield stress developed in response to the magnetic field. When a rheological fluid is exposed to the appropriate energy field, the solid particles in the fluid align. This particle alignment causes the fluid's viscosity to decrease or increase. Viscosity is the rate of deformation of a fluid due to imposed shear stress. The emphasis in this section is on the first two distinct materials: ER and MR.

\section{Electrorheological (ER) fluids}

Observation of the ER characteristic went back to Winkler in 1784. However, Winslow further systematically studied ER property changes in 1947, and accordingly the ER phenomenon is sometimes referred to as the Winslow effect. ER fluids are colloidal suspensions that dramatically change properties when an appropriate electrical field is applied. Normally, ER fluids behave like normal Newtonian fluids. However, the linear structures that form when an electric field is applied hinder the free flow of the ER fluid. ER fluids under the influence of an electric field as small as $3 \mathrm{kV} / \mathrm{mm}$ behave like Bingham plastics, with a dynamic yield stress on the order of $10 \mathrm{kPa}$. In addition, the transformation time required for an ER fluid to change yield stress and viscosity characteristics is only a few milliseconds. Thus, ER fluids can change from a liquid to a solidlike structure almost instantly, which is highly advantageous in engineering applications [87].

\section{Magneto-rheological (MR) fluids}

MR fluids contain magnetizable particles: fibrous carbon suspended in a carrier fluid. Ferrometallic particles, such as carbonyl iron and other compounds are used as the magnetizable particles; silicon oil can be used as the carrier fluid. The MR fluid may also contain a surfactant to enhance the suspension of the solid magnetized ferrometallic particles. When an electrical current is applied to these fluids, the flow characteristics are changed almost instantly. Thus, a fluid with low viscosity can be made viscous by simply applying a magnetic field controlled electrically. The degree to which the viscosity is altered is proportional to the magnitude of the magnetic field applied $[88,89]$.

The major difference between ER and MR fluids is the appropriate applied energy fields. The ER fluids are those that respond to high-voltage and low-current electric fields, whereas MR fluids respond to magnetic fields, operate on battery voltage, and generate high fluid shear stress [90]. There is another difference concerning their efficiency. ER fluids require thousands of volts for operation and yield low shear stresses. With this much energy needed, there is obvious concern for safely containing the voltage and packaging the product to satisfy design requirements. Because MR fluids respond magnetically, they do not need the high voltage as ER fluids do, and MR fluids usually produce a much higher 


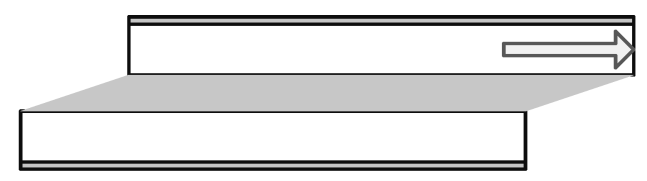

(a)

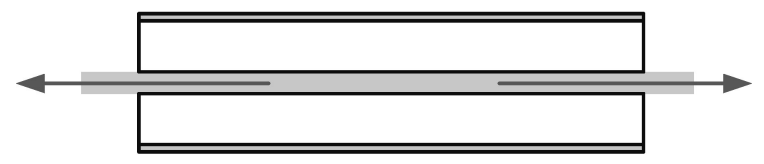

(b)

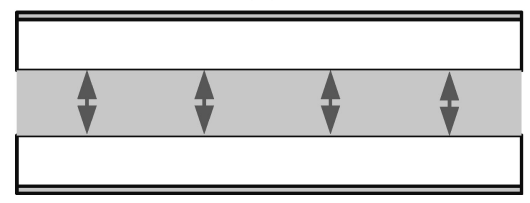

(c)

Figure 4. Three fundamental ER/MR design principles. (a) Direct shear mode, (b) Valve mode, and (C) Squeeze film mode.

shear stress compared to ER fluids. MR fluids also exhibit very low shear resistance at zero field, high shear stresses at maximum applied field, low hysteresis, chemical inertness, temperature stability, and fast response time.

There are three basic design modes of ER/MR devices and systems. The first is the direct shear mode (or the sliding plate mode) in which one of the permanent magnets or electrodes moves and the fluid experiences a shearing effect. The second is the valve mode (or the fixed electrode mode) in which the fluid is sandwiched between two stationary permanent magnets or electrodes resulting in an imposed flow field between the electrodes. The last mode is the squeeze film mode (or the fixed volume mode) where the force and displacement of the fluid are parallel to the magnetic poles or electrodes. Figure 4 illustrates the three design and application principles. Controllable applications of ER/MR fluids include active vibration isolation, control, dampers [91], squeeze film damping devices [92], active vehicular shock absorbers [88, 93], engine mounts [94], rotary active control damper [90], and so on.

\section{POLYELECTROLYTE GELS}

Ionic polymeric gels are polymeric solutions that possess the ability to alter their physical properties depending on imposed environmental conditions, such as $\mathrm{pH}$, electrical fields, electrical charge, light, and so forth. Katchalsky and Kuhn reported the swelling and shrinking of polymeric acids by ionization in 1949. Many new polymers were discovered between the years of 1988 and 1991, but not much theoretical work was begun until the early 1990s. Many of the earlier polymers had to be tested to determine the properties they exhibited. Even now theories that exist for the prediction of polymer behavior do not encompass all the gels; some gel properties still have to be experimentally determined [95].

Ionic polymeric gels (with some exceptions) expand and contract with changes in various imposed environmental factors. There are generally four competing forces acting on the gel polymer: the elasticity, the polymer-liquid viscous interaction, the inertial effect, and the electrophoretic/ionic interaction and ion pressure. It has been known for some time that gels consisting of ionic polymers deform when an electric field is applied through the solution emerging the gel. Swelling/contraction is a complex phenomenon depending 
on $\mathrm{pH}$, salt concentrations, and electric field strength $[96,97]$. The gel volume is determined by opposing effects. Swelling of the gel is induced by attractive interaction between polymer and solvent. The other is the elasticity of the solution, which counteracts expansion. This should determine the overall volume of the polymeric gel. However, if the gel contains electrical charges, the ions within the gel are not equivalent to those outside the gel; hence, an electrical imbalance is induced, and further expansion/contraction is induced.

When gels are brought into an alkaline or acidic environment, the behavior of the gel is modified. When an imbalance of ions occurs in an acidic region, expansion of the gel tends to be less severe than if the same polymer is brought into an alkaline region, that is, gels shrink in acidic solution and swell in alkaline solution. Furthermore, it appears that expansion of a neutral gel solution is similar to that of an alkaline solution except at high and low ionic concentrations. Initially, these two kinds of functional groups are considered to be oppositely charged and electrostatically bound to each other. In alkaline solution, the amino groups will be neutralized, and the sulfonate groups will remain negatively charged. Therefore, electrostatic linkage between the two functional groups will disappear, and the electrostatic repulsion between sulfonate groups will contribute to the swelling of the gel. Such electrostatic repulsion between the similarly charged groups is known to contribute to the swelling cross-linked polymer gel. For the acidic solution, sulfonate groups will remain negatively charged, and the electrostatic bond will not disappear, resulting in no swelling.

When an electric field is applied, an imbalance is induced within the gel, and contraction/expansion occurs. Behavior of a cationic gel under the influence of an electric field can be explained as follows. First, the anode side shrinks if the gel is contacting with the anode, whereas the anode side swells and then shrinks if the gel is sufficiently separated from the anode. Second, the cathode shrinks slightly in both contacting and noncontacting cases. Additionally it is interesting to note that the deformation of the gel is inversely proportional to the square of the applied current; and if the diffusion of the ions are the same, the deformation is further governed by the dominant ions, alkaline or acidic.

Thus, actuators, self-correcting devices, or regulators are their natural applications. Examples include artificial corneas [98], gas sensors [99, 100], medical implants, drug delivery systems, artificial fingers [101, 102], muscles [95, 103], robotics actuators [104], optical waveguides [105], adhesives, and membranes and integrated force arrays [104], just to mention a few. Future research, development, and applications still need to be explored.

\section{PYROELECTRIC MATERIALS}

Pyroelectricity is defined as an instantaneous polarization of crystals in response to a temperature differential. Pyroelectric crystals were first mentioned by the Greek philosopher Theophrastus, who described lyncurium - a material known to have the property of attracting thin bits of metal or wood [106, 107]. This attraction was later shown to result from thermal effects, which caused an inhomogeneous change of the pyroelectric material's temperature. This, in turn, caused charges to form on the ends of the pyroelectric crystals [108]. Of the 32 point groups of crystals, 20 groups are piezoelectric and only 10 groups qualify as pyroelectric. All pyroelectrics are a subgroup of the piezoelectrics, a crystal group characterized by polarization due to mechanical strain [6]. In most applications, five common pyroelectric materials are used: triglycine sulfate, lithium tantalate, strontium barium niobate, PVDF, and ceramic materials based on lead zirconate [109]. Tourmaline is one of the best-known pyroelectric crystals. Several varieties exist, with the dark varieties having 
little or no pyroelectric effect. This is due to the high conductivity of the darker varieties. The effects in tourmaline are basically secondary with only $10-20 \%$ due to primary pyroelectricity. Tourmaline crystals were observed to attract dust particles during heating and cooling [107].

Pyroelectricity may be further divided into two categories: vectorial and tensorial. Vectorial pyroelectricity, the most common, may be defined as the change with temperature of positive and negative polarization charges on certain portions of crystals belonging to certain classes. Similarly, tensorial pyroelectricity manifests itself in the production of small charges of like sign at edges occurring at the ends of certain axes, when the crystal is heated uniformly. Tensorial pyroelectricity is concerned with the quadrupole moments in crystals and is theoretically applicable to all crystal structures except cubic. Uniform heating causes changes in the field in the immediate neighborhood of the quadrupoles with the result that double layers of electricity appear at the surface [6, pp. 699-711].

The total pyroelectricity of a crystal consists of two parts: a primary component corresponding to a temperature differential on a completely contained crystal, and a secondary component dealing with the piezoelectric deformation that occurs due to the rising temperature and thermal expansion [110-112]. Secondary pyroelectric effects may be further subdivided according to whether heating is uniform. These are referred as the first kind and the second kind, representing nonuniform and uniform heating, respectively. The converse of pyroelectricity is the electrocaloric effect, which is known as the change in temperature of a pyroelectric crystal caused by a change in the electric field [6]. This is generally a very small quantity, but in some cases, like Rochelle salt, is not to be considered negligible. Pyroelectric devices are primarily applied to temperature-related measurements or infrared detection [113]. Several useful applications for pyroelectric materials include the measurement of thermal parameters [114], x-ray generation, electrostatic attraction, the testing of reflectivity [115], vehicle monitoring [116], infrared CCD camera [117, 118], integrated circuit monitoring [119], and so on.

\section{OPTOELECTRO/MAGNETO MATERIALS}

Three photoelectro/magneto material classes and their applications are reviewed in this section. The first class encompasses the photostrictive materials, the second encompasses the photoferroelectric materials, and the third the magneto-optical materials. The first class can be used as both sensor and actuator, whereas the second and the third are primarily used as information storage devices, although the magneto-optical materials are often used to manipulate and control light orientations in optical systems. Material characteristics, control mechanisms, and practical applications are discussed.

\section{Photostrictive materials}

Photostriction (or optopiezoelectricity) is a photodeformation process that includes two fundamental opto-electromechanical effects: the photovoltaic effect and the converse piezoelectric effect [22, 120-125]. Figure 5 illustrates the photostrictive effect and the photodeformation process. Photostrictive ceramics are ferrodielectric ceramics that have a photostrictive effect. PLZT is a photostrictive material with the general formula [ $\mathrm{Ph}$, $\mathrm{La})(\mathrm{Zr}, \mathrm{Ti}) \mathrm{O}_{3}$ ] that can be utilized as photostrictive actuators. PLZT ceramics are fabricated in a hot-forging process using $\mathrm{PbO}, \mathrm{TiO}_{2}, \mathrm{ZrO}_{2}$, and $\mathrm{La}_{2} \mathrm{O}_{3}$ powders with $\mathrm{Nb}_{2} \mathrm{O}_{3}$ as a dopant and are then hot-forged to create a PLZT ceramic. The $\mathrm{TiO}_{2}$ and $\mathrm{ZnO}_{2}$ powders are mixed and hall milled in acetone, producing a dry powder after drying. This mixture is then combined with $\mathrm{PbO}$ and $\mathrm{LaO}_{3}$ and $\mathrm{NbO}_{3}$ as a dopant. This new mixture is ball 


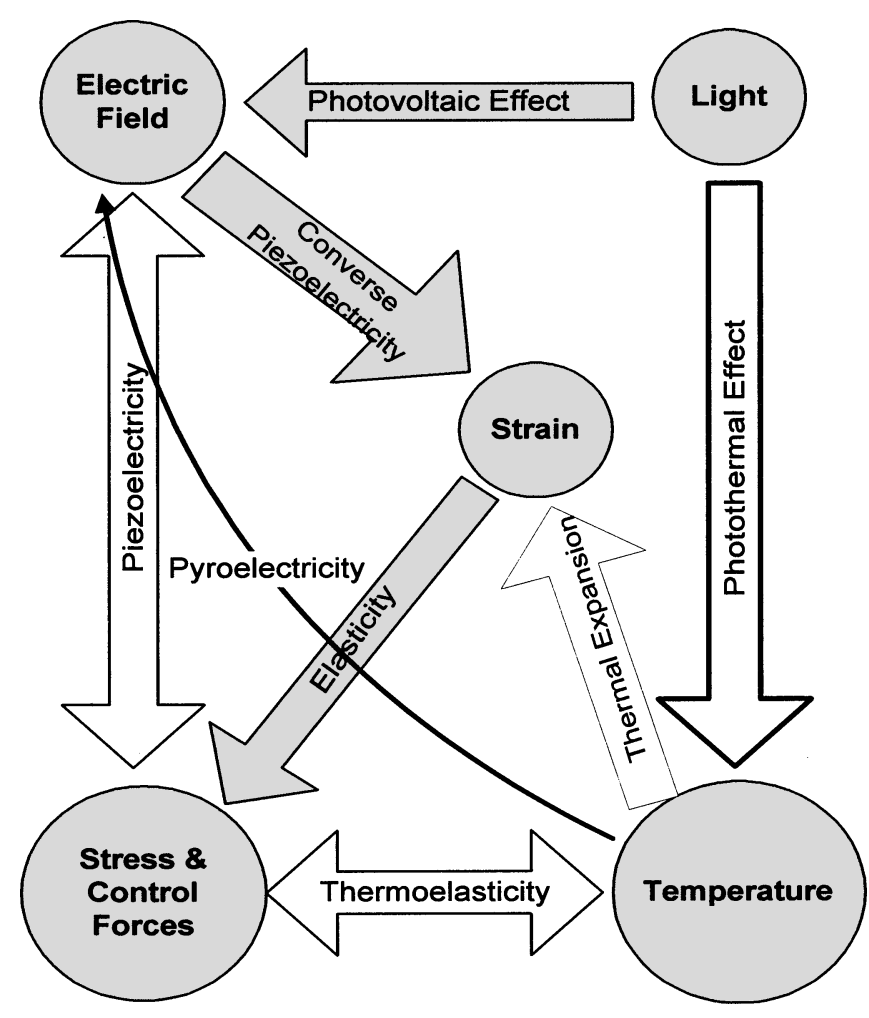

Figure 5. Photodeformation and photostriction characteristics.

milled in acetone, also producing a dry powder when evaporated. The powder is calcined and then sifted to produce a particle size of $0.3-0.2 \mu \mathrm{m}$. The final operation is to form the PLZT powder to the desired shape by cold-pressing the powder and then sintering at 1000$1150^{\circ} \mathrm{C}$ in oxygen. The PLZT material can be made denser by hot-forging to a temperature of $1175-1275^{\circ} \mathrm{C}$ at $800-1200$ psi for $1-3 \mathrm{~h}$. This will achieve a density of $98.5 \%$ of the material's theoretical maximum density. The result of the Nb-doped PLZT ceramic is an increased maximum strain and fatigue life over conventionally fabricated PLZT materials in addition to reduced strain hysteresis [126].

A photostrictive actuator system is usually made of two-layer photosensitive materials which are bonded together in opposite polarity, that is, the bimorph configuration with their planar spontaneous polarities opposite to each other. It is assumed that the bonding adhesive layer provides a perfect bonding and the viscoelastic effect can be neglected. The bonding layer is assumed opaque to light transmission. Accordingly, the irradiated light is absorbed on the top layer and no light penetrates into the bottom layer. When the top surface is irradiated by a uniform high-energy illumination, the absorbed light energy on the top layer induces a current on the top layer due to the photovoltaic effect and this current flows opposite to its polarized direction [120]. The induced current flow charges the end surface paired electrodes and thus generates an in-plane electric field. Consequently, a positive strain is generated in the top illuminated layer and a negative strain is generated in the bottom dark layer due to the converse piezoelectric effect. This coupling effect causes the photostrictive optical actuator to deform convexly (the photodeformation effect), and accordingly distributed actuation and control can be induced [22, 125]. The 
magnitude of photodeformation is on the order of microns applicable to precision actuation and micromachines.

Note that PLZT ceramics, when utilized as a photostrictive device, have a response time many orders of magnitude slower than piezoelectric materials. In general, the response takes the first-order form with the exponential characteristics [127]. The discharge response could be three times slower than the charge response. Accordingly, the photostrictive materials are effective for precision static or quasi-static actuation and control applications. Recent studies have also investigated the feasibility of distributed optoelectromechanical actuators applied to distributed vibration control of plates and shells [22, 123-125]. To make PLZT ceramics a viable active material utilized as dynamic optical actuators, the response time has to be significantly improved. Ongoing research is addressing this issue with much success. Furthermore, because high-energy lights drive the actuators, the actuator can be activated via wireless noncontact light sources without any hardwire connections or physical contact. Thus, these actuators can be used in hostile environments (e.g., nuclear radiation, chemical contamination, strong electromagnetic fields, etc.). Other practical applications include photophones [128], optical switchs [129], microactuators [130], optical projection systems [131], optorobots [132], and so forth.

\section{Photoferroelectric materials}

Photoferroelectric materials such as lead lanthanum zirconate titanate have been used to store information for many years [121]. These materials become relatively polarized when a light signal is applied to the material. The combination of a positive bias voltage and light exposure causes the ferroelectric domains to reorient or reverse in the exposed regions while remaining unchanged in the unexposed regions. The maximum resolution of images stored in these materials, bulk ceramic plates, was found that the minimum size of a pixel (image resolution element) is approximately four to five grain diameters. The minimum grain size that has been obtained in these materials is about $1 \mu \mathrm{m}$ and the minimum pixel size is about 4 to $5 \mu \mathrm{m}$. The light is transmitted through a polycrystalline ceramic plate; when it encounters refractive index mismatches at grain and domain boundaries, it produces depolarization and light scattering. Switching times for these materials are on the order of tens of microseconds for ceramic plates of photoferroelectric materials. Correlation devices have a wide variety of present applications and even wider variety of future uses. These devices provide a way for determining whether an externally perceived object matches or looks like a known object. Examples of devices might include intrusion detection systems, terrain identification systems, and critical alignment systems. One of the most important characteristics of new devices is that they perform at a great speed without the need for many optical components or slow mechanical scanning components. Other applications include a new laser centering device used in stereolithography systems.

\section{Magneto-optical materials}

In 1845, Michael Faraday discovered that a polarized light passing through a piece of heavy glass attached to the poles of a powerful electromagnet changed its polarized angles. This effect later became known as the magneto-optical effect, or the Faraday effect. A linearly polarized light passing through a magneto-optical material placed in a magnetic field will remain linearly polarized, but the plane of polarization will be rotated. The net rotation of the plane of polarization is equal to the product of the material thickness, the magnetic field strength, and the Verdet constant influenced by both temperature and wavelength $[133,134]$. 
A beam of polarized light can be approximated as two counter-rotating beams of light. The linear polarized light passing through the magneto-optical material is equal to two polarized components: a right circularly polarized component and a left circularly polarized component. Each component is affected differently by the magnetic field, and they each enter the magneto-optical material at different speeds. When the light comes out the other side, the left and right circular components are out of phase and after superposition they become a linearly polarized light beam with the polarization rotated relative to its original orientation. Although Faraday discovered the magneto-optical effect in 1845, very little was done to practically utilize this technology until recent years.

One application of the Faraday effect and magneto-optical material is as an optical or light isolator. The isolator is a device that permits electromagnetic waves to travel in only one direction. Usually, a Faraday rotator is placed between a polarizer and an analyzer such that polarized light is rotated $45^{\circ}$ counterclockwise by the Faraday rotator. This light and orientation travel completely through the analyzer with no distortion. Optical elements farther down the line cause undesirable backreflections (retropulses), but by passing the light beam (including backreflections) through the Faraday rotator a second time, the polarized light is rotated another $45^{\circ}$. The polarized light then encounters the polarizer at an angle of $90^{\circ}$, and the polarizer rejects this $90^{\circ}$ light beam - preventing the light from returning back to the system where it could damage optical components. The isolator isolates the system from stray light waves.

Another common use of magneto-optical materials is data recording in magneto-optical media, regardless of whether it is called magnetic or optical. The fundamental principle of a magneto-optical memory device is relatively simple. Common magnetic media have a low coercivity at room temperature; that is, the Curie point for regular magnetic media approximates room temperature. The Curie point basically indicates the temperature at which the magnetic field on a material can be permanently altered. Because regular magnetic media have a low coercivity, they are prone to being erased by being exposed to an external magnetic field. One of the biggest advantages of optical and magneto-optical data storage is that the Curie point is relatively high, and regardless of the strength of the magnetic field the storage units are placed under, the permanently stored data on the disk will not be affected unless the media are heated to a temperature above the Curie point [135, 136].

Magneto-optical disks of the magnetic field modulation mode are used in data files and other advanced applications. The magnetic field modulation mode records signals in a magneto-optical disk by directing a laser beam from an optical head to the recording layer in a DC manner by raising the temperature of the irradiated spot and applying a modulated magnetic field across the recording layer from a magnetic head opposed to the optical head at the same time. Therefore, the magnetic field modulation mode allows for overwrite recording and has potential application to rewritable compact disks. Many other mechatronic applications utilize magneto-optical materials to vary the polarity of light (on or off) to send digital signals. Because these signals are sent through light beams, they can be significantly faster and better to work with than typical electronic digital signals, because the mass of photons is much less than that of electrons. With the constant accelerations and decelerations present in a computer chip, the design of chips has become much more complicated than it could be with the use of these optical signals. Furthermore, magneto-optical material can be used in computers for three-dimensional memory or in printheads [137] to obtain up to 300 dots per inch or even in fluids to detect the amount of magnetic debris present. Future mass data storage systems depend on the development of magneto-optical materials and systems. Other applications include laser radars [138], infrared detection [139], and optical shutters [140]. 


\section{SUPERCONDUCTING MATERIALS}

In 1911, Kamerlingh Onnes first observed that the resistance of mercury wire vanished as the temperature approached absolute zero. This observation led into a new age of superconductivity. Electrical resistance in metallic conductors arises due to material impurities, defects, and ion vibrations within the lattice structure at normal temperature. However, as one lowers the temperature of some materials, the resistance due to the vibrating ions decreases. In many nonmagnetic elements, alloys, and compounds, when the temperature drops below a certain value, the critical temperature, the material enters into a superconductive state [141]. In a superconductor, all resistance due to the ion vibration is removed as the temperature drops below the critical temperature. This leaves the resistance as a function of the impurities and defects within the material. Thus, the resistivity of a superconductor can be reduced to less than $10^{-12}$ of a specimen at normal temperatures [142].

There are two important effects influencing the operation of superconductors and their applications. The first one is the Meissner-Ochsenfeld effect. For cylinders and spheres of superconducting materials, once the critical temperature is reached, the material expels all magnetic fields [141]. The second effect is the Josephson effect, which consists of two parts. The first, the DC Josephson effect, involves the movement of electrons. Consider two superconductors separated by a very thin insulator. Pairs of electrons, called Cooper pairs, can cross the insulating material into the other superconductor. The movement of the Cooper pairs across the insulator, called tunneling, results in what is called a supercurrent. In short, a current is created without applying a potential difference. The second of the Josephson effects is the AC effect. This arises from the fact that when a DC potential difference is applied across a configuration like the one just described, an AC supercurrent results. This phenomenon may be used to measure a DC potential difference very accurately. One common use of the Josephson effects is in superconducting quantum interference devices (SQUIDs). A SQUID is a device that is used to detect very weak, external magnetic fields. Its basic operation is fairly simple. A supercurrent is split at a junction and joined at a second junction. The phase difference between the Cooper pairs for each path, as measured at the second junction, is dependent on the path and the magnetic flux through the loop. Thus, the current at the second junction varies with the properties of the external magnetic field.

There are three types of superconductors. The first, type-I, has two very distinct states. The state of the material is determined by a combination of the temperature and the external magnetic field. If the field is very weak (weaker than the critical field $B_{\mathrm{c}}$ ) and the temperature very low (lower than the critical temperature $T_{\mathrm{c}}$ ), the material will be in the superconducting state. Otherwise, the material is considered to be in its normal state. It should be noted that type I superconductors were the first discovered. However, superconductivity in these materials is very hard to maintain. This is primarily because they are the lowest temperature superconductors and are readily affected by external magnetic fields. Thus, they are also the least useful in practical applications.

The second group of superconductors are the type II superconductors. Though these materials remain superconducting to a much higher temperature than their type I counterparts, they can also exist in a mixed state. This state, which resides between the purely superconductive and the normal state, occurs when the external magnetic field is greater than the first critical field $\left(B_{\mathrm{c} 1}\right)$ but less than the second $\left(B_{\mathrm{c} 2}\right)$ at a given critical temperature. In the mixed state, the solid consists of thin cores or filaments existing in the normal state. While the cores are in the normal state, the surrounding material is in the superconductive state. The superconductive material contains a current that flows around each core. This, in turn, produces a magnetic flux through each core [141]. 
The third type of superconductors is the high-temperature variety, which are sometimes referred to as the type III superconductors. Although little is known about how or why these work, they do show great promise for commercial applications. The type III superconductors are primarily derived from metal oxides (ceramics) and it does appear as though the heavier, in terms of molecular weight, the compound is, the higher its critical temperature. As of 1988 the highest critical temperature reached for a superconductor was $125 \mathrm{~K}$ for Tl-Ca$\mathrm{Ba}-\mathrm{Cu}-\mathrm{O}$. However, in 1993 a superconducting family derived from a base of $\mathrm{Hg}-\mathrm{Cu}-\mathrm{O}$ was discovered to have superconductive properties up to roughly $160 \mathrm{~K}$ [143]. These hightemperature superconducting oxides have the important economical advantage of operating with a less-expensive refrigerant such as liquid nitrogen, rather than metallic materials that require more expensive refrigerants such as liquid helium [144].

Engineering applications can be mainly divided into two categories: (1) sensing devices and (2) motors and actuators. Recall that the SQUID is an extremely sensitive sensing device detecting superweak magnetic fields. Sample motor and actuator applications are discussed here. In damping and levitation application, NASA developed a system using superconductors to control and protect cryogenic instruments in spacecraft and aircraft by means of load-bearing support and vibration damping [145]. The system consists of a combination of two components, a cold chamber containing a cryogenic instrument and a separate flux source outside the cold chamber. Within the cold chamber, a superconductive material is used in the delicate cryogenic instrument. A flux source, such as an ordinary ferrite magnet, is placed outside the cold chamber, with a copper winding encompassing it. The copper winding in turn is attached to a resistor. As the instrument moves within the cold chamber, the Meissner effect (the magnetic effect associated with supercooled superconductive materials) of the superconductive material reacts to the permanent ferrite magnet outside the cold chamber to stabilize its motion. The energy associated with this

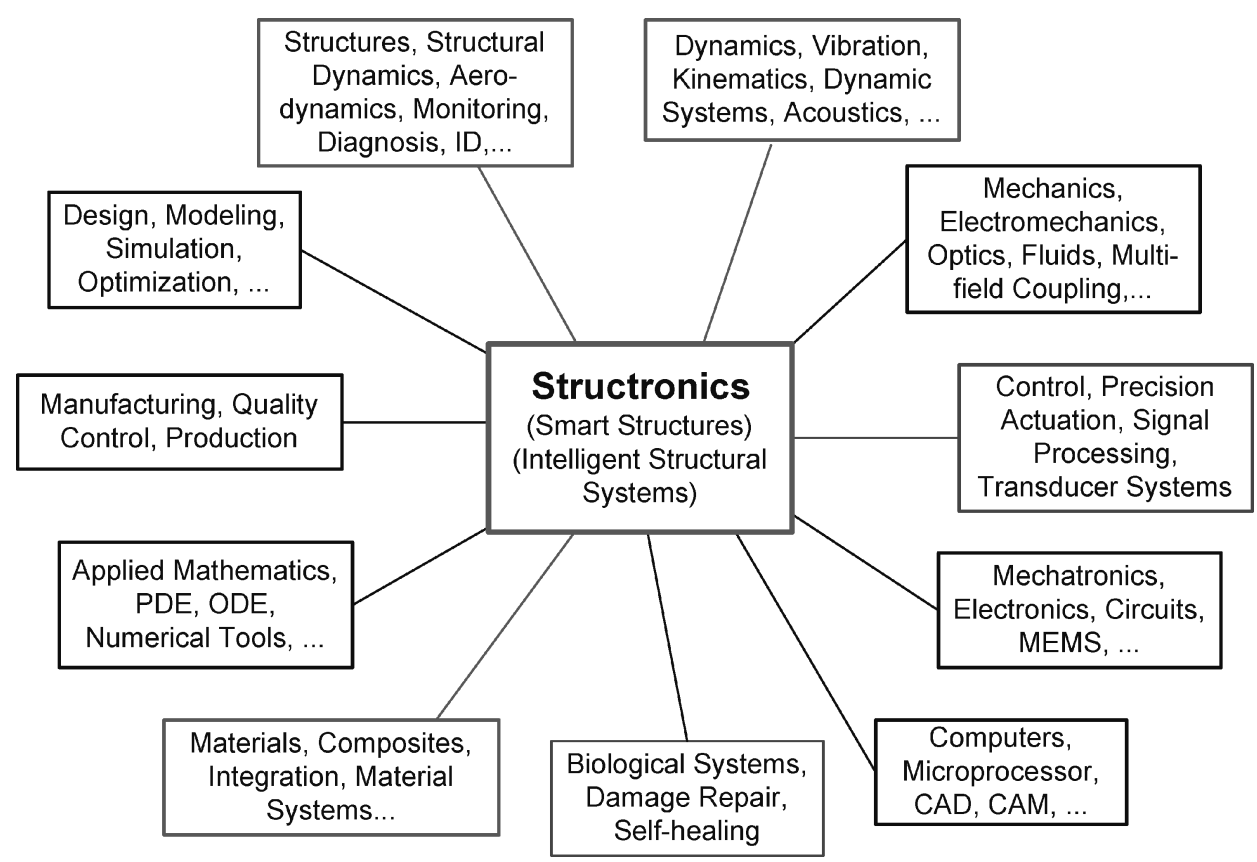

Figure 6. Structronics-a multidiscipline integration. 
vibration is transformed into magnetic field energy and then converted into a current through a copper coil surrounding the ferrite magnet. The electrical energy is then dissipated through the linear resistor element. Also, the levitation principle is applied to ground vehicles with improved electromagnetic suspension and propulsion [146].

A superconducting rotor stabilizer was reported recently. The restraint in the rotor system is caused by the magnetic flux of the rotor permanent magnet penetrating into the superconducting bearing device spaced at a predetermined distance. Thus, the device supports a rotatable member with good stability and a relatively simple construction [147]. Electric motors using high-temperature superconducting materials were recently proposed. In conventional motors, the peak radial flux density is limited by iron core saturation, core loss, and the ability to produce and sustain a field with windings that are prone to emitting strong magnetic fields. The peak current density is limited by heat transfer considerations and space limitation. New high-temperature superconductive windings (HTSC) in electric motors create large air gap magnetic fields without any electrical losses. HTSC emits almost twice the peak flux radial densities of conventional motors, resulting in reductions in motor

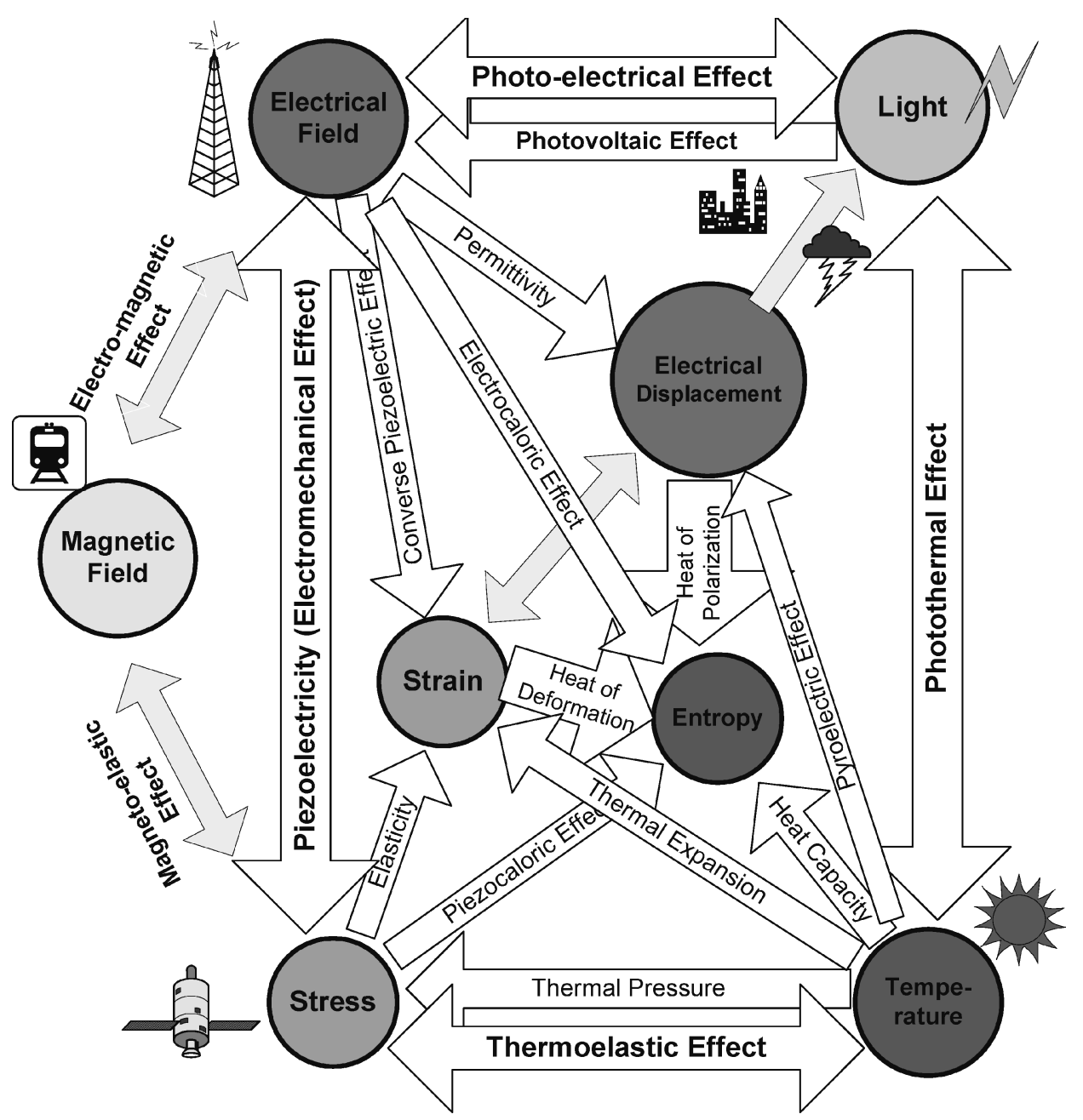

Figure 7. Multifield coupling of smart materials/structures and structronic systems. 
size and motor losses. The only drawback is the required cost and complexity of maintaining a cryogenic cooling (liquid nitrogen) system to cool the superconductive windings. In a superconductive motor, the only magnetic material in the motor is the outer layer preventing the magnetic field losses. However, the liquid nitrogen cooling system is still much cheaper than the liquid helium cooling system used in the old (low-temperature) superconducting motor system [148]. Another superconducting permanent magnetic motor was also recently reported [149]. Levitation and driving mechanism for high-speed bullet trains, based on superconductors, have been studied and experimented upon recently.

\section{CONCLUSION}

Active controllable smart electro/magneto materials provide new dimensions and design opportunities for precision and high-performance devices, structures, mechatronic systems, and structronic systems. Synergistically integrating smart materials, sensors/actuators, control electronics, computers, and artificial intelligence further enhances conventional mechatronic devices or systems to a new generation of fully integrated smart structures and structronic systems. Accordingly, the new smart structures and structronic systems technology truly represent a systematic synergistic integration of conventional disciplines and applications as shown in Figure $6[1,4]$.

To reflect the state of the art, this paper provides an overview of a number of smart materials (e.g., piezoelectrics, shape-memory materials, electro- and magnetostrictive materials, and MR fluids, polyelectrolyte gels, pyroelectrics, photostrictive materials, photoferroelectrics, magneto-optical materials (Table 1), superconductor devices, and novel optothermoelectromagnetomechanical transducer (sensor/actuator) systems. Histories,

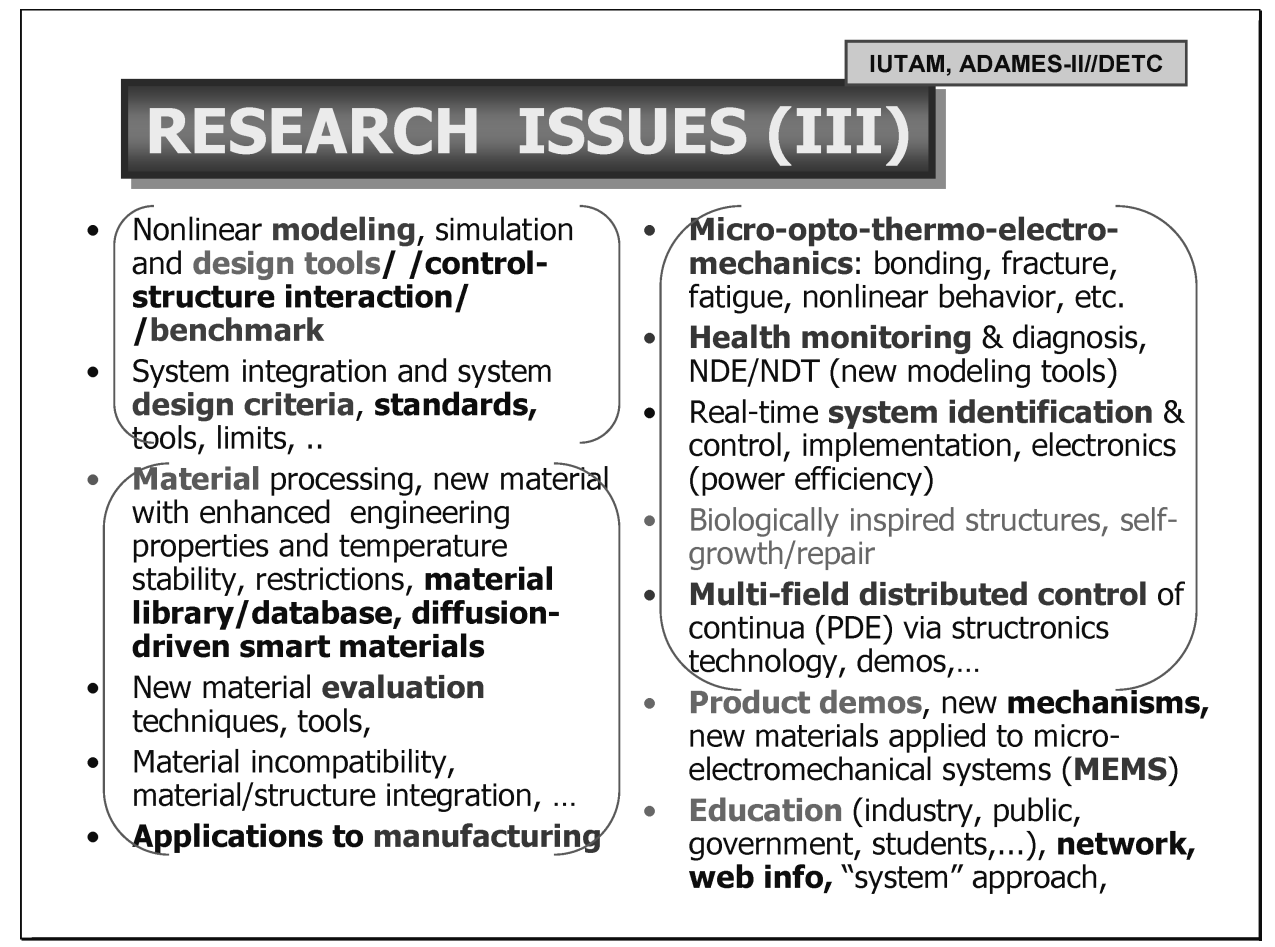

Figure 8. Research issues in smart structures and structronic systems. 
characteristics, design principle, control mechanisms, material varieties, and practical applications were emphasized.

The new smart structures and structronics technology also poses many challenging research issues regarding the coupled multifield phenomena and control mechanisms. Figure 7 illustrates the multifield optomagnetothermoelectromechanical coupling of structronic systems. Figure 8 outlines current research issues discussed in a number of technical panels at recent ASME and international conferences. It is clear that plenty of challenges and opportunities need to be addressed in order to fully utilize this new technology to advance industries and to benefit human life in the near future.

\section{REFERENCES}

[1] H. S. Tzou and U. Gabbert, STRUCTRONICS—A New Discipline and Its Challenging Issues, Smart Mechanical Systems-Adaptronics, pp. 245-250, Fortschritt-Berichte VDI, Düsseldorf, Germany, 1997.

[2] H. S. Tzou, A. Guran, U. Gabbert, J. Tani, and A. Breitbach (eds.), Structronic Systems-Smart Structures, Devices, and Systems, vol. 2, Systems and Control, World Scientific, NJ /Singapore, 1998.

[3] H. S. Tzou and G. L. Andeson (eds.), Intelligent Structural Systems, Kluwer, Dordrecht/Boston/ London, 1992.

[4] U. Gabbert and H. S. Tzou (eds.), Smart Structures and Structronic Systems, IUTAM Symposium on Smart Structures and Structronic Systems, Kluwer, Dordrecht/Boston/London, 2001.

[5] H. S. Tzou and M. C. Natori, Piezoelectric Materials and Continua, Encyclopedia of Vibration, pp. 1011-1018, Academic Press, London, UK, 2001.

[6] W. G. Cady, Piezoelectricity, Dover, New York, 1964.

[7] M. C. Dökmeci, Dynamic Applications of Piezoelectric Crystals, Shock Vib. Dig., vol. 15, pp. 9-22, 1983.

[8] W. P. Mason, Piezoelectric Crystals and Their Application to Ultrasonics, Nostrand, New York 1950.

[9] R. D. Mindlin, On the Equations of Motion of Piezoelectric Crystals, in J. Radok (ed.), Problems on Continuum Mechanics, pp. 282-290, Society for Industrial and Applied Mathematics, Philadelphia, 1961.

[10] R. D. Mindlin, High Frequency Vibrations of Piezoelectric Crystal Plates, Int. J. Solid Struct., vol. 8, pp. 895-906, 1972.

[11] H. F. Tiersten, Linear Piezoelectric Plate Vibration, Plenum, New York, 1969.

[12] N. T. Adelman and Y. Stavsky, Axisymmetric Vibrations of Radially Polarized Piezoelectric Ceramic Cylinders, J. Sound Vib., vol. 38, pp. 245-254, 1975.

[13] N. T. Adelman and Y. Stavsky, Vibrations of Radially Polarized Composite Piezoelectric Cylinders and Disks, J. Sound Vib., vol. 43, pp. 37-44, 1975.

[14] M. C. Dökmeci, Theory of Vibrations of Coated, Thermopiezoelectric Laminae, J. Math. Phys., vol. 19, pp. 109-126, 1978.

[15] H. S. Tzou and M. Gadre, Theoretical Analysis of a Multi-Layered Thin Shell Coupled with Piezoelectric Shell Actuators for Distributed Vibration Control, J. Sound Vib., vol. 132, pp. 433 450, 1989.

[16] H. S. Tzou, Piezoelectric Shells (Distributed Sensing and Control of Continua), Kluwer, 1993.

[17] N. N. Rogacheva, The Theory of Piezoelectric Shells and Plates, CRC Press, Boca Raton, FL, 1994.

[18] H. S. Tzou and Y. Bao, A Theory on Anisotropic Piezothermoelastic Shell Laminates with Sensor/Actuator Applications, J. Sound Vib., vol. 184, pp. 453-473, 1995.

[19] H. S. Tzou and Y. Bao, Nonlinear Piezothermoelasticity and Multi-Field Actuations, Part-1: Nonlinear Anisotropic Piezothermoelastic Shell Laminates, J. Vib. Acoust., vol. 119, pp. 374381, 1997. 
[20] H. S. Tzou and Y. Bao, Analysis of Nonlinear Piezothermoelastic Laminated Beams with Electric and Temperature Effects, J. Sound Vib., vol. 209, pp. 505-518, 1998.

[21] H.-J. Lee and D. A. Saravanos, A Mixed Multi-Field Finite Element Formulation for Thermopiezoelectric Composite Shells, Int. J. Solid Struct., vol. 37, pp. 4949-4967, 1999.

[22] H. S. Tzou, B. J. Liu, and D. Cseledy, Optopiezothermoelastic Actions and Micro-Control Sensitivity Analysis of Cylindrical Opto-Mechanical Shell Actuators, J. Theor. Appl. Mech., vol. 3, pp. 775-796, 2002.

[23] W. P. Mason, Piezoelectricity, Its History and Applications, J. Acoust. Soc. Am., vol. 70, pp. 1561-1566, 1981.

[24] G. M. Sessler, Piezoelectricity in Polyvinylidene Fluoride, J. Acoust. Soc. Am., vol. 70, pp. 1596-1608, 1981.

[25] H. S. Tzou and T. Fukuda (eds.), Precision Sensors, Actuators, and Systems, Kluwer, Dordrecht/Boston/London, 1992.

[26] H. S. Tzou and L. A. Bergman (eds.), Dynamics and Control of Distributed Systems, Cambridge University Press, New York, 1998.

[27] E. F. Crawley and J. de Luis, Use of Piezoelectric Actuator as Elements of Intelligent Structures, AIAA J., vol. 25, pp. 1373-1385, 1987.

[28] S. Hanagud and M. W. Obal, Identification of Dynamic Coupling Coefficients in a Structure with Piezoelectric Sensors and Actuators, AIAA paper 88-2418, AIAA, 1988.

[29] H. S. Tzou, Integrated Distributed Sensing and Active Vibration Suppression of Flexible Manipulators Using Distributed Piezoelectrics, J. Robotic Syst., vol. 6, pp. 745-767, 1989.

[30] D. L. Polla, Micromachining of Piezoelectric Microsensors and Microactuators for Robotics Applications, Tzou and Fukuda (eds.), Precision Sensors, Actuators and Systems, pp. 139-174, Kluwer, Dordrecht/Boston/London, 1992.

[31] X. H. Jian, H. S. Tzou, C. J. Lissenden, and L. S. Penn, Damage Detection Using Piezoelectric Patches-Free Vibration Approach, J. Compos. Eng., vol. 31, pp. 345-359, 1997.

[32] J. M. Plumb, J.E. Hubbard, and T. Bailey, Nonlinear Control of a Distributed System: Simulation and Experimental Results, J. Dyn. Syst.-Trans. ASME, vol. 109, pp. 133-139, 1987.

[33] A. Baz and S. Poh, Performance of an Active Control System with Piezoelectric Actuators, J. Sound Vib., vol. 126, pp. 327-343, 1988.

[34] H. S. Tzou, Active Vibration Control of Flexible Structures via Converse Piezoelectricity, Developments in Mechanics, Proceedings of the 20th Midwestern Mechanics Conference, vol. 14, pp. 1201-1206, 1987.

[35] H. S. Tzou and Y. Zhou, Nonlinear Piezothermoelasticity and Multi-Field Actuations, Part2: Control of Nonlinear Buckling and Dynamics, J. Vib. Acoust., vol. 119, pp. 382-389, 1997.

[36] L. Librescu, L. Meirovitvh, and S. S. Na, Control of Cantilever Vibration via Structural Tailoring and Adaptive Materials, AIAA J., vol. 35, pp. 423-433, 1997.

[37] A. B. Palazzolo, R. R. Lin, R. R. Kascak, and R. M. Alexander, Active Control of Transient Rotordynamic Vibration by Optimal Control Methods, J. Eng. Gas Turb. Power, vol. 111, p. 265, 1989.

[38] J. J. Dosch, D. J. Inman, and E. Garcia, A Self-Sensing Piezoelectric Actuator for Collocated Control, J. Intel. Mater. Syst. Struct., vol. 3, pp. 166-185, 1992.

[39] E. H. Anderson, N. W. Hagood, and J. M. Goodliffe, Self-Sensing Piezoelectric Actuation: Analysis and Application to Controlled Structures, 33rd SDM Conf., AIAA Paper 92-2465CP, 1992.

[40] H. S. Tzou and J. J. Hollkamp, Collocated Independent Modal Control with Self-Sensing Orthogonal Piezoelectric Actuators (Theory and Experiment), J. Smart Mater. Struct., vol. 3, pp. 277-284, 1994.

[41] C. K. Lee and F. Moon, Modal Sensors/Actuators, IBM Rep RJ 6306 (61975), Research Division, IBM, 1988.

[42] H. S. Tzou, J. P. Zhong, and M. C. Natori, Sensor Mechanics of Distributed Shell Convolving Sensors Applied to Flexible Rings, J. Vib. Acoust., vol. 115, pp. 40-46, 1993. 
[43] H. S. Tzou, J. P. Zhong, and J. J. Hollkamp, Spatially Distributed Orthogonal Piezoelectric Shell Actuators: Theory and Applications, J. Sound Vib., vol. 177, pp. 363-378, 1994.

[44] J. L. Fason and J. A. Gabra, Experimental Studies of Active Members in Control of Large Space Structures, AIAA paper 88-2207, 1988.

[45] H. T. Banks and R. C. Smith, Numerical Techniques for Simulation, Parameter Estimation, and Noise Control in Structural Acoustic Systems, in H. S. Tzou and L. A. Bergman (eds.), Dynamics and Control of Distributed Systems, pp. 202-263, Cambridge University Press, New York, 1998.

[46] H. S. Tzou and M. Gadre, Active Vibration Isolation and Excitation by a Piezoelectric Slab with Constant Feedback Gains, J. Sound Vib., vol. 136, pp. 477-490, 1990.

[47] A. Baz and J. Ro, The Concept and Performance of Active Constrained Layer Damping Treatments, Sound Vib., vol. 28, pp. 18-21, 1994.

[48] H. S. Tzou, R. Ye, and J. H. Ding, A New X-Actuator Design for Controlling Wing Bending and Twisting Modes, J. Sound Vib., vol. 241, pp. 271-281, 2001.

[49] H. S. Tzou, W. K. Chai, and D. W. Wang, Modal Voltages and Micro-Signal Analysis of Conical Shells of Revolution, J. Sound Vib., vol. 260, pp. 589-609, 2003.

[50] H. S. Tzou, J. H. Ding, and I. Hagiwara, Micro-control Actions of Distributed Actuators Laminated on Deep Paraboloidal Shells, JSME Int. J. C., Special issue on Dynamics and Design of Continuous Systems, vol. 45, pp. 8-15, 2002.

[51] H. S. Tzou, J. H. Ding, and P. Smithmaitrie, Electric Circuit Design and Testing of Integrated Distributed Structronic Systems, J. Sound Vib., vol. 257, pp. 931-943, 2002.

[52] H. S. Tzou, P. Smithmaitrie, and J. H. Ding, Sensor Electromechanics and Distributed Signal Analysis of Piezo(Electric)-Elastic Spherical Shells, Mech. Syst. Signal Pr., vol. 16, pp. 185199, 2002.

[53] H. S. Tzou and D. W. Wang, Distributed Dynamic Signal Analysis of Piezoelectric Laminated Linear and Nonlinear Toroidal Shells, J. Sound Vib., vol. 254, pp. 203-218, 2002.

[54] H. S. Tzou and D. W. Wang, Vibration Control of Toroidal Shells with Parallel and Diagonal Piezoelectric Actuators, J. Press. Vess.-Trans. ASME, vol. 125, pp. 171-176, 2003.

[55] H. S. Tzou, D. W. Wang, and W. K. Chai, Dynamics and Distributed Control of Conical Shells Laminated with Full and Diagonal Actuators, J. Sound Vib., vol. 256, pp. 65-79, 2002.

[56] T. Lynch, Piezoelectric Damper Hones Ski Performance, reprint Des. News, February 5, 1996.

[57] S. Ashley, Smart Skis and Other Adaptive Structures, Mech. Eng., vol. 117, pp. 76-81, 1995.

[58] P. M. Galletti, D. E. De Rossi, and A. S. De Raggi, Medical Applications of Piezoelectric Polymers, Gordon and Breach, New York, 1988.

[59] S. Ueha, Y. Tomikawa, M. Kurosawa, and N. Nakamura, Ultrasonic Motors, Clarendon Press, Oxford, 1993.

[60] T. Sashida and T. Kenjo, An Introduction to Ultrasonic Motors, Clarendon Press, Oxford, 1993.

[61] K. Uchino, Piezoelectric Actuators and Ultrasonic Motors, Kluwer Academic, Dordrecht/ Boston/London, 1997.

[62] D. E. Hodgson, Engineering Aspect of Shape Memory Alloy, Proceedings, Butterworth Scientific, Lansing, MI, 1988.

[63] D. L. Schetky, Shape Memory Effect Alloys for Robotic Devices, Robotic Age, July, pp. 13-17, 1984.

[64] R. N. Boggs, How Memory Metals Shape Product Designs, Des. News, vol. 49, pp. 72-74, June 1993.

[65] D. Stoeckel, Shape Memory Actuators for Automotive Applications, Mater. Des., vol. 11, pp. 302-307, 1990.

[66] H. Funakubo, Shape Memory Alloys, Gordon and Breach, New York, 1984.

[67] S. Hirose, K. Ikuta, and M. Tsukamoto, Development of a Shape Memory Alloy Actuator, $A d v$. Robotics, vol. 4, pp. 3-27, 1990.

[68] M. A. Ealey and P. A. Davis, Standard SELECT Electrostrictive Lead Magnesium Niobate Actuators for Active and Adaptive Optical Components, Opt. Eng., vol. 29, pp. 1373-1382, 1990. 
[69] C. L. Hom, M. Pilgrim, N. Shankar, K. Bridger, M. Massuda, and S. R. Winzer, Calculation of Quasi-Static Electromechanical Coupling Coefficients for Electrostrictive Ceramic Materials, IEEE Trans. Ulrason. Ferr., vol. 41, pp. 542-552, 1994.

[70] J. Galvagni, Electrostrictive Actuators and Their Use in Optical Engineering, Opt. Eng., vol. 29, pp. 1389-1391, 1990.

[71] Y. Kondou and T. Ono, A Displacement Generating Apparatus, U.S. Patent no. 5,083,056, 1992.

[72] A. Visscher, M. P. Koster, and J. W. Weekamp, Electromechanical Displacement Device and Actuator Suitable for Use in Such a Electromechanical Displacement Device, U.S. Patent no. $5,465,021,1995$.

[73] M. Kawamura, A Controller for a Vibration Wave Motor, U.S. Patent no. 5,500,578, 1996.

[74] A. R. Rathore, A Valve Arrangement for a Micropump, U.S. Patent no. 5,520,522, 1996.

[75] T. Yamauchi, T. Nogi, and Y. Ohyama, Fuel Injection Valve and Fuel Supply System Equipped Therewith for Internal Combustion Engines, U.S. Patent no. 5,099,815, 1992.

[76] K. Hikita, H. Iizuka, and Y. Tanaka, Optical Scanner, U.S. Patent no. 5,253,098, 1993.

[77] W. K. Chai and H. S. Tzou, Constitutive Modeling of Controllable Electrostrictive Thin Shell Structures, Symposium on Advances of Solids and Structures (PVP-8), 2002 ASME International Mechanical Engineering Congress, Paper no. IMECE2002-32328, New Orleans, LA, November 17-22, 2002.

[78] H. S. Tzou, W. K. Chai, and S. M. Arnold, Micro-Structronics and Control of Hybrid Electrostrictive/Piezoelectric Thin Shells, 2003 ASME Adaptive Structures and Material Systems Symposium, Paper no. IMECE2003-42398, Washington, DC, November 16-21, 2003.

[79] D. G. Dixon, Magnetostrictive Clamp, U.S. Patent no. 5,101,183, 1992.

[80] J. M. Vranish, Magnetostrictive Roller Drive Motor, U.S. Patent no. 5,079,460. 1992.

[81] R. Porzio, W. J. Harrold, and J. R. Sturges, Self-Biased Modular Magnetostrictive Driver and Transducer, U.S. Patent no. 4,845,450, 1989.

[82] E. Garcia and L. D. Jones, Self-sensing Control Applied to Smart Material Systems, in A. Guran and H. S. Tzou (eds.) Structronic Systems-Smart Structures, Devices, and Systems, Volume 1: Materials and Structures, pp. 37-60, World Scientific Publishing, New Jersey/Singapore, 1998.

[83] D. L. Hall and A. B. Flatau, Broadband Performance of a Magnetostrictive Shaker, Act. Control Noise Vib., DSC-vol. 38, pp. 95-104, 1992.

[84] S. Klein, Sperical Membrane Omnidirectional Loudspeaker Using A Magnetostrictive Bimettalic Strip, U.S. Patent no. 5,103,483, 1992.

[85] J. M. Sewell and W. F. Werner, Low Frequency Sound Transducer, U.S. Patent no. 4,907,209, 1990.

[86] D. E. Parker and M. Markay, Helical Magnetostrictive Core Line Hydrophone, U.S. Patent no. 4,965,778, 1990.

[87] J. D. Carlson, A. F. Sprecher, and H. Conrad (eds.), Electrorheological Fluids, Technomic, Lancaster, Pennsylvania, 1989.

[88] T. E. Duclos, Electrorheological Fluids: A Materials and Applications Primer, in H.S. Tzou, A. M. Baz, T. E. Duclos, and D. J. Inman (eds.), Intelligent Structural Systems, Lecture Notes SC-5, 1994 North American Conference on Smart Structures and Materials, Orlando, FL, February 17-18, 1994.

[89] K. D. Weiss, High Strength Magneto- and Electro-Rheological Fluids, SAE Paper 932415, pp. 1-6, 1993.

[90] A. Pinkos, E. Shtarkman, and T. Fitzgerald, Active Damping Using ERM Fluids, Automot. Eng., vol. 101, pp. 19-23, 1993.

[91] S. A. Austin, The Vibration Damping Effect of an Electrorheological Fluid, J. Vib. Acoust., vol. 115 , pp. 136, 1993.

[92] S. Morishita and J. Mitsui, Controllable Squeeze Film Damper (An Application of Electrorheological Fluid), J. Vib. Acoust., vol. 114, pp. 354, 1992. 
[93] T. G. Duclos, J. D. Carlson, M. J. Chrzan, and J. P. Coulter, Electrorheological FluidsMaterials and Applications, in H. S. Tzou and G. L. Anderson (eds.), Intelligent Structural Systems, pp. 213-241, Kluwer Academic, Dordrecht/Boston/London, 1992.

[94] S. Morishita and J. Mitsui, ER Fluid Engine Mounts, Automot. Eng., February, pp. 52-55, 1993.

[95] M. Shahinpoor, Active Polyelectrolyte Gels as Electrically Controllable Artificial Muscles and Intelligent Network Structures, in Tzou et al.(ed.) Structronic Systems-Smart Structures, Devices, and Systems, Volume 2: Systems and Control, World Scientific Publishing, NJ/Singapore, pp. 31-85, 1998.

[96] Y. Osada, H. Okuzaki, and H. Hori, A Polymer Gel with Electrically Driven Motility, Nature, vol. 355, pp. 242-243, 1992.

[97] M. Doi, M. Matsumota, and Y. Hirose, Deformation of Ionic Polymer Gels by Electric Fields, Macromolecules, vol. 25, pp. 5504-5511, 1992.

[98] T. V. Chirila, Interpentrating Polymer Network (IPN) as a Permanenet Joint Between the Elements of a New Type of Artificial Cornea, J. Biomed. Mater. Res., vol. 28, pp. 745-753, 1994.

[99] S. Dogan, U. Akbulut, T. Yalcin, S. Suzer, and L. Toppare, Conducting Polymers of Aniline II. A Composite as a Gas Sensor, Synthetic Met. vol. 60, pp. 27-30, 1993.

[100] P. N. Bartlett and S. K. Ling-Chung, Conducting Polymer Gas Sensors, Part III: Results for Four Different Polymers and Five Different Vapours, Sensor Actuator, vol. 20, pp. 287-292, 1989.

[101] O. Shiga, Y. Hirose, and K. Kurauchi, Electroviscoelastic Effect of Polymeric Composites Consisting of Polyelectrolyte Particles and Polymer Gel, Smart Mater. Struct., pp. 1293-1299, Champman \& Hall, New York, 1993.

[102] T. Shiga, Y. Hirose, et al., Electrically Driven Polymer Gel Finger Working in the Air, J. Intel. Mater. Syst. Struct., vol. 4, pp. 553-557, 1993.

[103] M. Shahinpoor, Electro-Thermo-Mechanics of Resilient Contractile Fiber Bundles as Robotic Actuators, 1994 IEEE Robotics and Automation Conf. Proceedings, vol. 1, pp. 1502-1507, IEEE, Piscataway, NJ, 1994.

[104] J. E. Bousaba, S. M. Bobbio, S. G. Johansson, M. D. Kellam, B. W. Dudley, J. D. Jacobson, S. K. Jones, T. D. DuBois, and F. M. Tranjan, Membrane Based Actuator-Integrated Force Arrays, 1994 IEEE Conference on Microelectromechanical Systems Proceedings, pp. 845-846, IEEE, Piscataway, NJ, 1994.

[105] H. U. Simmrock and C. Bubeck, Optical waveguiding in Thin Films of Polyelectrolytes, J. Appl. Phys., vol. 24, pp. 1003-1008, 1990.

[106] S. B. Lang, Ferroelectrics, vol. 33, pp. iii-iv, Gordon and Breach, New York, 1981.

[107] S. B. Lang, Sourcebook of Pyroelectricity, Gordon and Breach, New York, 1982.

[108] V. K. Novik and N. D. Gavrilova, The State of the Art in Pyroelectricity, Ferroelectrics, vol. 34, pp. 47-55, Gordon and Breach, New York, 1981.

[109] S. G. Porter, A Brief Guide to Pyroelectric Detectors, Ferroelectrics, vol. 33, pp. 193-206, Gordon and Breach, New York, 1981.

[110] H. S. Tzou and R. V. Howard, A Piezothermoelastic Shell Theory Applied to Active Structures, J. Vib. Acoust., vol. 116, pp. 295-302, 1994.

[111] H. S. Tzou and R. Ye, Piezothermoelasticity and Precision Control of Piezoelectric Systems: Theory and Finite Element Analysis, J. Vib. Acoust, vol. 116, pp. 489-495, 1994.

[112] H. S. Tzou and R. Ye, Pyroelectric and Thermal Strain Effects in Piezoelectric (PVDF and PZT) Devices, Mech. Syst. Signal Pr., vol. 10, pp. 459-479, 1996.

[113] P. E. Dyer and R. Srinivasan, Pyroelectric Detection of Ultraviolet Laser Ablation Products from Polymers, J. Appl. Phys., vol. 66, pp. 2608-2611, 1989.

[114] S. Bauer and B. Ploss, Interference Effects of Thermal Waves and Their Application to Bolometers and Pyroelectric Detectors, Sensor Actuator, vol. 25-27, pp. 417-421, 1991.

[115] R. J. Batt, Application of Pyroelectric Devices for Power and Reflectance Measurements, Ferroelectrics, vol. 34, pp. 11-14, Gordon and Breach, New York, 1981. 
[116] T. Hussain, A. M. Baig, T. N. Saadawi, and S. A. Ahmed, Infrared Pyroelectric Sensor for Detection of Vehicle Traffic Using Digital Signal Processing Techniques, IEEE Trans. Veh. Technol., vol. 44, pp. 683-688, 1995.

[117] G. Hofmann, L. Walther, J. Schieferdecker, N. Neumann, V. Norkus, M. Krauss, and H. Budzier, Construction, Properties and Application of Pyroelectric Single-Element Detectors and 128Element CCD Linear Arrays, Sensor Actuator, vol. 25-27, pp. 413-416, 1991.

[118] M. Okuyama, Y. Togami, Y. Hamakawa, M. Kimata, and S. Uematsu, Pyroelectric InfraredCCD Image Sensor Using $\mathrm{LiTaO}_{3}$, Sensor Actuator, vol. 16, pp. 263-271, 1989.

[119] W. V. Munch and U. Thiemann, Pyroelectric Detector Array with PVDF on Silicon Integrated Circuit, Sensor Actuator, vol. 25-27, pp. 167-172, 1991.

[120] P. S. Brody, Optomechanical Bimorph Actuator, Ferroelectrics, vol. 50, pp. 27-32, 1983.

[121] V. M. Fridkin, Photoferroelectrics, Springer-Verlag, New York, 1979.

[122] K. Uchino, Photostrictive Actuator, Proc., 1990 IEEE Ultrasonics Symposium, pp. 721-723, 1990.

[123] H. S. Tzou, Distributed Optical Actuators, Adapt. Struct. Mater. Syst., AD-vol. 35, pp. 165-170, 1993.

[124] B. Liu and H. S. Tzou, Distributed Optical Actuation and Opto-Piezothermoelasticity Applied to Vibration Control of Plates, J. Vib. Acoust., vol. 120, pp. 937-943, 1998.

[125] H. R. Shih and H. S. Tzou, A New Class of Distributed Photostrictive Orthogonal Actuators in Smart Curved Structures, 2001 Adaptive Structures and Materials Symposium (Aero), 2001 ASME International Mechanical Engineering Congress, Book no. I00521, Paper no. AD23721, CD-vol. 3, New York, NY, November 12-17, 2001.

[126] R. R. Nuergaonkar and J. R. Oliver, Method of Fabricating PLZT Piezoelectric Ceramics, U.S. Patent no. 5,607,632, 1997.

[127] H. S. Tzou and C. S. Chou, Nonlinear Opto-Electromechanics and Photodeformation of Distributed Optical Actuators, J. Smart Mater. Struct., vol. 5, pp. 230-235, 1996.

[128] B. Holmes, Polymer Lights the Way to Optical Computing, New Sci. vol. 144, p. 23, 1994.

[129] J. Wilson, Optical Switch That Needs No Power, Electron. World Wirel., vol. 99, p. 715, 1993.

[130] J. Suski, D. Largeau, A. Steyer, F. C. M. van de Pol, and F. R. Blom, Optically Activated $\mathrm{ZnO} / \mathrm{SiO}_{2} / \mathrm{Si}$ Cantilever Beams, Sensor Actuator, vol. 24, pp. 221-225, 1990.

[131] T. Browning, Optical Projection Systems, U.S. Patent no. 4,951,150, 1990.

[132] T. Fukuda, S. Hattori, F. Arai, H. Matsuura, T. Hiramatsu, Y. Ikeda, and A. Maekawa, Characteristics of Optical Actuator-Servomechanisms Using Bimorph Optical Piezoelectric Actuator, Proceedings, IEEE Robotics and Automation Conf., Atlanta, GA, pp. 618-623, May 1993.

[133] F. L. Pedrotti and L. S. Pedrotti, Introduction to Optics, 2nd ed., Prentice Hall, Englewood Cliffs, New Jersey, 1993.

[134] H. S. Tzou, Multifield Transducers, Devices, Mechatronic Systems, and Structronic Systems, Shock Vib. Dig., vol. 30, pp. 282-294, 1998.

[135] M. Mansuripur, The Physical Principles of Magneto-Optical Recording, Cambridge University Press, New York, 1995.

[136] T. W. McDaniel and H.V. Randall, Handbook of Magneto-Optical Data Recording: Materials, Subsystems, Techniques, Noyes Publications, Westwood, New Jersey, 1997.

[137] E. E. Price, Magneto-Optic and Fiber-Optic Digital Print Head, U.S. Patent no. 4,899,222, 1990.

[138] B. C. Redman et al., Magneto-Optical Arrangement for Laser Radar, U.S. Patent no. 5,500,729, 1996.

[139] A. Gartenberg et al., Magneto-Optical Input System for Infrared Detectors, U.S. Patent no. $5,491,334,1996$.

[140] T. Ohara, Optical Shutter Using Magneto-Optical Materials, U.S. Patent no. 5,050,968, 1990.

[141] H. Benson, University Physics, pp. 882-886, John-Wiley and Sons, New York, 1991.

[142] E. A. Avallone and T. Baumeister, Marks' Standard Handbook for Mechanical Engineers, 9th ed., pp. 19.24-19.29, McGraw-Hill, New York, 1987. 
[143] A. P. Malozemoff, Superconducting Wire Gets Hotter, IEEE Spectrum, vol. 30, pp. 26-30, 1993.

[144] W. F. Smith, Foundations of Material Science and Engineering, 2nd ed., McGraw-Hill, New York, 1993.

[145] B. P. Dolgin, Superconductive Material and Magnetic Field for Damping and Levitation Support and Damping of Cryogenic Instruments, NASA Patent Application SN:08/077,470, June, 1993.

[146] F. R. Huson, Ground Vehicle Suspension and Guidance and Electromagnetic System Thereof with Multiple Surface Arcuate Reaction Rails, U.S. Patent no. 5,085,149, 1992.

[147] R. Takahata, N. Shoji, and E. Osaka, Superconducting Bearing Device Stabilized by Trapped Flux, U.S. Patent no. 5,330,967, 1994.

[148] J. D. Edick, R. F. Schiferl, and H. E. Jordan, High Temperature Supreconductivity Applied to Electric Motors, IEEE Trans. Appl. Supercon., vol. 2, pp. 189-194, 1992.

[149] P. Tixador, C. Berriaud, and Y. Brunet, Superconducting Permanent Magnet Motor Design and First Tests, IEEE Trans. Appl. Supercon., vol. 3, pp. 381-384, 1993. 